\section{Barriers to dietary modifica- tions for people living with type 2 diabetes in a rural indigenous Guatemalan community}

\author{
Julia Wilson, ${ }^{1}$ James Svenson, ${ }^{2}$ \\ Sean Duffy, ${ }^{3}$ Jessica Schmidt ${ }^{2}$ \\ ${ }^{1}$ Department of Internal Medicine, \\ Medical College of Wisconsin; \\ ${ }^{2}$ Department of Emergency Medicine \\ University of Wisconsin; ${ }^{3}$ Department of \\ Family Medicine, University of \\ Wisconsin, WI, USA
}

\begin{abstract}
In Guatemala, the prevalence of diabetes continues to increase with a disproportionate burden falling on indigenous rural communities. In this study, we assessed barriers to making dietary modifications for people living with type 2 diabetes in a rural indigenous Guatemalan population. Structed interviews $(n=32)$ were conducted with participants selected from a convenience sample of adults with type 2 diabetes living in villages in and around San Lucas Tolimán, Guatemala. Frequencies were calculated for closed-ended questions and content analysis was used to evaluate open-ended questions. Most participants (81\%) were women with low-levels of formal education and average daily food expenditure of just over \$1 USD. The majority of participants were able to identify foods important in a diabetic diet, however, with significant barriers to making dietary modifications. Commonly cited perceived barriers included high costs of food due to travel and storage, inadequate local access to fresh fruits and vegetables and incompatibility with traditional diet. Several structural and cultural barriers exist to prevent dietary modifications for people living with type 2 diabetes in this rural indigenous population.
\end{abstract}

\section{Introduction}

The prevalence of type 2 diabetes has been increasing over the past few decades; roughly 463 million adults are living with diabetes worldwide; and the majority live in low and middle income countries. ${ }^{1}$ Although medical care plays in an important role in type 2 diabetes management, modifiable lifestyle factors, especially diet, are essential in maintaining improved health outcomes and decreasing patients' risk for other serious health conditions such as cardiovascular disease. ${ }^{2}$ Barriers to dietary modification for people with diabetes may be magnified for those living in remote and rural areas such as the indigenous populations of Guatemala. Studies from other rural populations found barriers to maintaining a healthful diet included lack of understanding of the diet plan, cost of diet, the perception of diabetic foods as bland or flavorless, and the burden of eating a different diet than the rest of the family. 3,4

In Guatemala, indigenous communities living in rural areas may face even greater challenges as they also suffer from historical and ongoing discrimination with poor access to care and documented abuse and discrimination when utilizing public health services. ${ }^{5-8}$ The Guatemalan Minister of Health has reported that rates of diabetes are increasing more rapidly in indigenous populations. ${ }^{9}$ The purpose of our study was to explore barriers to dietary modification for people living with diabetes in a primarily indigenous population in rural Guatemala. To our knowledge, this is the first study to exclusively explore barriers to dietary modifications in an indigenous Guatemalan population.

\section{Materials and Methods}

\section{Study site}

San Lucas Tolimán is a town of mostly indigenous highland Maya with a population of 17,000 people in South-Central Guatemala on Lake Atitlan. There is an additional population of about 14,000 spread among 19 rural communities scattered around San Lucas (ISEM 2020). The average income is less than $\$ 1,000$ USD per year, or about \$3 USD per day (INE 2015). A health promoter program, coordinated by a local religiously-affiliated NGO hospital and physician, provides basic medical care and health education, including diabetes care, to these surrounding communities. Participants in the diabetes program undergo regular education with community health promoters and attend a monthly diabetes clinic where blood glucose and hemoglobin A1c are monitored and medications adjustment accordingly. ${ }^{10}$ The health promoters are community members with basic training in disease identification and treatment of common illnesses including type 2 diabetes. ${ }^{11}$ The closest government district hospital is in Sololá, $40 \mathrm{~km}$ away.

\section{Study population}

Participants were identified and recruit-
Correspondence: Jessica Schmidt, Department of Emergency Medicine, University of Wisconsin, 800 University Bay Drive, Suite 310, 53705Madison, WI, USA.

Tel.: +1.608.890.8682 - Fax +1.608.265.8241

E-mail: jschmidt@medicine.wisc.edu

Key words: Diabetes; indigenous; diet.

Acknowledgments: We wish to thank Dr. Rafael Tun at San Lucas Hospital and the health promotors, Cesia Castro Chuta, Dominga Pic Salazar, and Rogelio Coroxon. We would also like to thank the Friends of San Lucas.

Contributions: JW conducted interviews, analyzed data and contributed to writing the manuscript, JES contributed to study design and editing manuscript, SD contributed as content expert and to manuscript editing, and JS contributed to study design, data analysis and manuscript writing. All authors read and approved the final manuscript.

Conflict of interests: The authors have no conflicts of interest to declare.

Further information: JW was supported by an educational research scholarship for travel by the Herman and Gwen Shapiro Foundation.

Availability of data and materials: All data generated or analyzed during this study are included in this published article.

Ethics approval and consent to participate: The study was determined exempt by the Institutional Review Board of the University of Wisconsin. Patients gave their consent to participate.

Informed consent: Informed consent was obtained from a legally authorized representative(s) for anonymized patient information to be published in this article.

Received for publication: 27 July 2021.

Revision received: 30 August 2021.

Accepted for publication: 1 September 2021.

This work is licensed under a Creative Commons Attribution 4.0 License (by-nc 4.0).

${ }^{\circ}$ Copyright: the Author(s), 2021

Licensee PAGEPress, Italy

Healthcare in Low-resource Settings 2021; 9:10002 doi:10.4081/hls.2021.10002

ed by health promotors in a convenience sample from a group people known to have type 2 diabetes. Inclusion criteria were: adults (age $>18$ years) with type 2 diabetes and Spanish speaking. Most individuals in this area are bilingual, speaking both Kaqchikel, the local Mayan language, and Spanish. Individual interviews were con- 
ducted at diabetic clinics held monthly in several villages in the area or during home visits. Interviews were conducted entirely in Spanish by a member of the research team (JW). JW had extensive knowledge of the local community and health promoter structure and was fluent in Spanish. Health promoters fluent in Kaqchikel were also available to clarify questions as necessary. Verbal consent was obtained for all participants in Spanish due to low literacy and consent was witnessed by the health promoters. Responses to questions were collected by the researcher using detailed handwritten notes at the time of the interview. Notes were taken instead of audio recording based upon cultural preferences identified by health promoters.

The study was determined exempt by the Institutional Review Board of the University of Wisconsin. The project was supported by the Friends of San Lucas organization and their health promoter program.

\section{Data collection}

The study employed a concurrent triangulation mixed-method design. ${ }^{12}$ We conducted structured interviews with questions designed to generate a combination of quantitative and qualitative results. The first portion of the 20-question interview guide contained close-ended questions regarding demographics, history of diabetes, and current medical treatment. The second set of questions involved a mix of open and closed-ended questions related to dietary consumption and food purchasing. The final set of open-ended questions focused on participants' understanding and beliefs about healthful foods for people with diabetes, perceived obstacles to dietary changes, and potential facilitators for maintaining a healthful diet.

In addition to responding to the structured questions, participants often willingly elaborated on their answers. Conversations also occurred around answers that were unclear. These additional comments were also captured in the researcher's notes, with relevant sections included for use in the qualitative analysis or to support quantitative results.

\section{Data analysis}

The answers to closed-ended questions were descriptively calculated as frequencies and means. Open-ended questions were analyzed qualitatively using content analysis. ${ }^{13}$ Two reviewers (JW and JS) performed coding with frequent cross-checks for accuracy. Questions relating to food purchasing and dietary behaviors (e.g.,"Can you tell me what you eat on a typical day for breakfast?") were coded into predetermined categories to determine response frequencies.
Other open-ended responses were coded by themes such as diet, food purchasing, cost, access, cultural norms, food preparation knowledge and healthful diet knowledge.

\section{Results}

Thirty-two participants were approached and all agreed to be interviewed (Table 1). The majority of the participants were middle-aged women with low levels of formal education. Participants were from six named communities (San Lucas Toliman 5 , Patulul 2, San Juan 4, Xexuju 1, Totolya 3, Tierra Santa 2). The remaining 15 participants described their community as 'rural' without an associated named community.

\section{Food purchasing}

The mean weekly per capita expenditure on food was reported to be 58.8 GTQ (7.85 USD). The majority of participants $(89 \%, n=28)$ shopped for food at an openair market. Of those who shopped at markets, most reported having to travel to an outside community, necessitating use of public transportation. Large open-air markets were only available at two of the local communities (Patulul and San Lucas Tolimán).

\section{Dietary patterns}

The typical diet of participants consisted primarily of tortillas and beans at mealtimes and occasional fruits for snacks throughout the week. Nearly all participants reported eating tortillas with all three of their daily meals $(94 \%, n=30)$; the average number of tortillas eaten per day by the individuals surveyed was 14 . The majority of participants also named beans as a central component of at least one meal of the day, with many having beans for two or more meals per day. Several participants reported eating fruits (the most commonly mentioned fruits being banana, mango, watermelon, and papaya) and liquados (fruit smoothies) several times per week for snacks. Several participants did incorporate hierbas (leafy greens) into a meal at least once per day, however, the majority of these participants admitted that this was typically not more than once a day and it was not daily. The most common beverage was atol (a milk based beverage made from ground corn that is often sweetened), and coffee, which were the main beverages aside from water. Most reported they drank unsweetened atol, whereas a small number had atol with sugar added. There was a wide variation in frequency of intake of atol, ranging from several 'cups' a week to 5 cups per day ('cups' were reported as a subjective measure).

\section{Dietary understanding}

When asked what foods were consistent with a healthful diet for people with diabetes, most participants answered with one or more of the following food groups: vegetables, hierbas (usually meaning leafy greens), lean meats, and "foods without sugar." Several participants cited changes they had made to incorporate healthful foods into their diet. For instance, one woman noted she no longer puts sugar in her coffee. Several others commented that they no longer ate soup broth or tried to eat comidas sin grasa (foods without fat.)

Four participants stated they did not know what foods were appropriate or that they had not changed diet at all. One participant noted that he just takes his medications and continues to eat the same foods.

\section{Perceived barriers}

When the participants were asked what prevented them from eating the foods they perceived as important to a healthful diet every day, the responses fell into several common groups: cost, access, family support and time required to prepare different foods, and lack of knowledge for food preparation

\section{Cost}

A majority of participants $(59 \%, n=19)$ reported that foods compatible with a healthful diet (namely vegetables and lean meats) were too costly. One patient, when asked what kept her from eating the foods important for a healthful diet, stated that she did not have enough money to buy enough food for her family in general. Another answered that he did not have enough money to afford many vegetables; if he is still hungry after he eats the vegetables his family does have, he just fills up on tortillas.

Table 1. Demographic characteristics of participants $n(\%)$.

\begin{tabular}{lc} 
Characteristic & Total n=32 \\
Gender & \\
Male (\%) & $6(19)$ \\
Female (\%) & $26(81)$ \\
Average age (years) & 53.5 \\
\hline Average age at diagnosis (years) & 46.5 \\
Level of formal education & \\
None (\%) & $20(63)$ \\
Elementary school (\%) & $10(31)$ \\
High school (\%) & $2(6)$ \\
Any college or higher education (\%) & 0 \\
\hline Positive family history of T2DM (\%) & $7(22)$ \\
\hline
\end{tabular}


Participants also cited fluctuations in income levels throughout the year with three "off-seasons" where cash was short. Several participants stated they had limited finances in general, not specifically constrained to diet.

For participants who did not perceive increased costs, few elaborated on reasons. One woman stated that initially costs were higher, but now she is "used to it." Others were unable to comment on cost because they did not monitor the food-related finances or did not do the shopping.

\section{Access}

Participants reported several factors that contributed to poor access to foods compatible with a healthful diet. Travel time and travel cost to the closest market were the most commonly cited barriers. A majority of the participants interviewed reported using public transportation to get to a market located between 5 and $30 \mathrm{~km}$ from their homes each time they wished to buy fresh foods. Because of difficulty with access and financial costs associated with this travel, participants typically only visited the fresh air market once every 7 to 15 days. In addition, participants did not have home refrigeration and foods would perish quickly. One patient stated that it was hard to buy enough vegetables to eat every day because they rot by the time he goes to the market again. Many participants explained that traveling for these types of foods is necessary because most perishable foods are not available at the corner stores in their home communities.

\section{Incompatibility with family and tra- ditional diet}

Many participants commented that eating a diabetic diet was difficult because they were preparing food differently for the person or people in the household with diabetes and the rest of the family members. Most participants were the only ones in their family with diabetes. No participants reported changing dietary habits for the entire family. One woman stated that eating a different diet was difficult because she had to prepare different foods for her husband and children and herself. Another stated it was difficult during festivals because family members may be eating foods like cake and he cannot.

\section{Potential facilitators}

When asked what would help them adhere more closely to a healthful diet, participants noted a variety of mediators including improved local access, local gardens, communal support, and improved knowledge of food preparation.

\section{Improved access}

Many participants commented on the lack of availability of fruits and vegetables in their home communities making travel to regional markets necessary. They also cited difficulties in acquiring fruits and vegetables year round due to variations in cost and travel time. Participants noted that they can buy several other items such as coffee and sugar at local corner shops and suggested stocking fruits and vegetables at these shops.

\section{Local gardens}

Participants proposed solutions to improved access by growing their own fruits and vegetables. One participant noted that he would benefit from land to grow his own vegetables. Another proposed a community garden be built at the rural diabetic clinics. The patient who presented this idea explained how the garden would both facilitate access to, and reduce the cost of, fresh vegetables for the people with diabetes living in his community.

\section{Communal support}

Several participants stated that having a community support group or small meetings would be beneficial. Often participants were the only ones in their family or small community with diabetes and only saw other people with diabetes at monthly diabetic clinic. One woman stated a support group would be helpful because it is difficult to do it all on her own.

\section{Improved knowledge in food prepa- ration}

Several participants mentioned that they knew what foods to eat but did not know how to prepare them. Participants described how foods important in a diabetic diet are often different from foods they traditionally eat such as tortillas, caldos (broths) and atol. They were also concerned that new foods would take more time to prepare and would have to be made separately from food for the rest of the family. Many participants suggested that videos or classes to teach them how to prepare healthful foods at home would be helpful.

\section{Discussion}

This study found that, despite a basic understanding of which foods are consistent with a healthful diet, indigenous people with type 2 diabetes living in rural Guatemala face significant barriers in complying with such a diet. Nearly all the participants interviewed in this study reported a diet that consisted primarily of corn tor- tillas and black beans, with only occasional fresh fruits and vegetables. These foods were typically prepared in the home and therefore a great degree of individual variation existed between serving size and ingredients. Participants stated that it was difficult to limit carbohydrate intake, primarily tortillas, as they are served ubiquitously at meals and are a part of the staple diet. Participants described difficulty in modifying their diet due to financial limitations, lack of access to fresh fruits and vegetables, lack knowledge of food preparation, and incompatibly with family norms.

The cost of maintaining a healthful diet can be a significant financial burden in this population. Nearly eighty percent of the indigenous population in Guatemala lives below the poverty line and $40 \%$ of this population lives in extreme poverty. Participants in this study reported spending little more than \$1 per person per day, on average, for food. Unsurprisingly, many cited the cost of recommended foods as a barrier to following a healthful diet. These answers are consistent with previous studies in indigenous populations in Guatemala; perishable foods such as fruits, vegetables, meats, and dairy products have consistently been perceived as too expensive to purchase regularly. ${ }^{3,14,15}$

Lack of access to fresh fruits and vegetables was also commonly cited as a barrier to eating a healthful diet. Participants reported that the small stores present in their communities do not regularly stock fruits, vegetables, and other fresh foods. This necessitated time-consuming and costly travel to larger communities using public transportation to purchase such foods. Most were only able to make this trip once every 1-2 weeks and did not have the means to store perishable food, resulting in poor availability and low consumption of such food. These findings are also supported by Webb et al., ${ }^{15}$ who described striking similarities between an indigenous rural community of Guatemala and the urban food deserts of the United States; there is an abundance of pre-packaged snack foods and sugar-rich beverages available, contrasted with an almost complete absence of fruits, vegetables, dairy, and fresh foods. Given the ubiquity of small stores in these rural communities, interventions to improve the availability of healthy, fresh food in these stores is another potential approach for improving the food environment. Such programs have been successful in improving access to fruits and vegetables in both urban and rural settings in high-income countries. ${ }^{16,17}$

Participants also suggested sustainable local models for ongoing access to fresh 
fruits and vegetables. These proposed solutions included increased access to land for gardens or community gardens. Community gardens have been shown to increase intake of fruits and vegetables for those with free access to the produce grown in the garden in high-income countries such as the United States. ${ }^{18}$ Similarly, studies conducted in Guatemala have found that families who maintain home gardens have superior nutritional status and access to fresh produce..$^{19,20}$

Other possible changes that may improve adherence to a healthful diet for people with diabetes in this area include community-based outreach with community support groups and classes in cooking and food preparation. Flood et al described a program in a similar population in the highlands of Guatemala where home visits were conducted with bilingual educators and, in addition to other interventions, improved outcomes for people with diabetes. ${ }^{21}$ Additional studies have shown that support groups can increase healthy lifestyle modifications for people living with diabetes..$^{22,23}$

\section{Limitations}

This study has several weaknesses that may limit its generalizability even within other indigenous Mayan populations. First, the participants in the study were identified by health promoters and may have held different views than the general population. In addition, the subset of participants were primarily middle-aged women, likely reflected by the fact that most indigenous men in this area are working in the fields during the day and may have different views from other people with type 2 diabetes in this area.

The participants were not blinded to the interviewer, a foreign woman. This may have biased the responses either due to concerns for trust or discretion. Health promoters were present during interviews in an effort to improve rapport and trust. Additionally, most participants are primary Kaqchikel speaking, with Spanish as a second language, and interviews were primarily conducted in Spanish with limited clarification by health promoters. This may have influenced participants understanding of questions or ability to adequately respond.

Finally, only one interviewer was present and took notes due to limitations in travel for the entire research team. This could lead to biases in recording and recall which would have downstream effects on data interpretation. Copious notes were taken in an effort to mitigate this bias.

\section{Conclusions}

A high-quality healthful diet is one of the most important modifiable lifestyle factors in preventing early mortality from type 2 diabetes; however, this is difficult and often unrealistic for rural indigenous people living in Guatemala. Participants in our study cited high costs of food due to travel and storage, inadequate local access to fresh fruits and vegetables, and incompatibility with traditional diet as barriers to dietary modications. Future studies are needed to assess strategies to help mitigate costs and improved access to allow these communities to improve and maintain a healthful diet.

\section{References}

1. World Health Organization. Diabetes. World Health Organization. Accessed: August 2021. Available from: https:/www.who.int/news-room/factsheets/detail/diabetes

2. Liu G, Li Y, Hu Y, et al. Influence of lifestyle on incident cardiovascular disease and mortality in patients with diabetes mellitus. J Am Coll Cardiol 2018;71:2867-76.

3. Nagelkerk J, Reick K, Meengs L. Perceived barriers and effective strategies to diabetes self-management. J Am Nursing 2006;54:151-8.

4. Juarez-Ramirez C, Theodore F, Villalobos A, et al. The importance of cultural dimension of food in understanding the lack of adherence to diet regimens among Mayan people with diabetes. Public Health Nutr 2019;17:3238-49.

5. Dean M, Bendfeldt G, Lou H, et al. Increased incidence and disparity of diagnosis of retinoblastoma patients in Guatemala. Cancer Lett 2014;351:5963.

6. Ippolito M, Chary A, Daniel M, Barnoya, et al. Expectations of health care quality among rural Maya villagers in Sololá Department, Guatemala: a qualitative analysis. Int J Equity Health 2017; 16:51.

7. Chomat AM, Solomons NW, Montenegro G, et al. Maternal health and health-seeking behaviors among indigenous Mam mothers from Quetzaltenango, Guatemala. Rev Panam Salud Publica 2014;35:113-20.

8. Ministry of Food and Nutritional Security (SESAN). Análisis de Situación, nutricional de Guatemala 2014. Accessed: Jan 2020. Available from: http://www.sesan.gob.gt/wordpress/w p - content/ u ploads/ 2017/07/PESAN-2016-2020.pdf

9. World Health Organization Ministry of Public Health and Social Assistance. Plan de acción 2008-2012 para la prevención y el control integral de las enfermedades crónicas y sus factores de riesgo. World Health Organization. Available from: https://www.mindbank.info/item/4622

10. Duffy S, Norton D, Kelly M, et al. Using Community Health Workers and a Smartpohne Application to Improve Diabetes Control in Rural Guatemala. Glob Health Sci Pract 2020;8:699-720.

11. Friends of San Luca. Health Promoter Program. Accessed: June 2020. Available from: https://sanlucasmission.org/programs/healthcare/

12. Creswell J, Plano Clark V. Designing and conducting mixed methods research. 2nd ed. Sage. Thousand Oaks, CA; 2011.

13. Elo S, Kyngäs H. The qualitative content analysis process. J Adv Nurs 2008;62:107-15.

14. Chary A, Greiner M, Bowers C, et al. Determining adult type 2 diabetes-related health care needs in an indigenous population from rural Guatemala: a mixed-methods preliminary study. BMC Health Serv Res 2012;12:476.

15. Webb M, Chary A, De Vries T, et al. Exploring mechanisms of food insecurity in indigenous agricultural communities in Guatemala: a mixed methods study. BMC Nutr 2016;2:55.

16. Fry C. Health on the Shelf: A Guide to Healthy Small Food Retailer Certification Programs. Accessed: June 2020. Available from: http://changelabsolutions.org/sites/default/files/Health on the Shelf FINAL 20130322web.pdf

17. Gittelsohn J, Laska M, Karpyn A, et al. Lessons learned from small store programs to increase healthy food access. Am J Health Behav 2014;38:307-15.

18. Barnidge E, Baker E, Schootman M, et al. The effect of education plus access on perceived fruit and vegetable consumption in a rural African American community intervention. Health Educ Res 2015;30:773-85.

19. Luna-González D and Sørensen M. Higher agrobiodiversity is associated with improved dietary diversity, but not child anthropometric status, of Mayan Achí people of Guatemala. Public Health Nutr 2018;2:2128-41.

20. Bodzio J, Nemeth E, DellaValle D. Assessing Food Insecurity and Family Gardens in Rural Indigenous 
Guatemala. J Acad Nutr Diet 22. Manning K, Senekal M, Harbron J. 2018;118:A81.

21. Flood D, Mux, S, Martinez, et al. Implementation and outcomes of a comprehensive type 2 diabetes program in rural Guatemala. PLoS One 2016;11:e0191152. for weight loss than usual care. Health SA 2019;24:1172.

23. Thankappan K, Sathish T, Tapp R, et al. A peer-supported lifestyle intervention for preventing type 2 diabetes in India: A cluster-randomized controlled trial of the Kerala Diabetes Prevention Program. PLoS Med 2018;15: e1002575. 